Running Head: Thermal comfort following immersion

\title{
Thermal comfort following immersion
}

Corresponding Author:

\section{Julien Guéritée}

University of Portsmouth, Department of Sport and Exercise Science, Portsmouth, U.K. Tel: +33 (0)6 78671493

43 avenue de Lissardy - Zuhaizti 2 - Haritza - Appt 09

64700 Hendaye - France

julien.gueritee@smart-celsius.fr

Bernard Redortier

Oxylane Research, Thermal Comfort Sciences,

Villeneuve d'Ascq, France

James R House

University of Portsmouth, Department of Sport and Exercise Science,

Spinnaker Building, Cambridge Rd, Portsmouth, U.K.

Michael J Tipton

University of Portsmouth, Department of Sport and Exercise Science, Spinnaker Building, Cambridge Rd, Portsmouth, U.K. 


\begin{abstract}
Unlike thermal comfort in air, little research has been undertaken exploring thermal comfort around water sports. We investigated the impact of swimming and cooling in air after swimming on thermal comfort. After 10 minutes of swimming-and-resting cycles in $28{ }^{\circ} \mathrm{C}$ water, volunteers wearing two types of garments or in swim briefs, faced winds in $24{ }^{\circ} \mathrm{C}$ air, at rest or when stepping. Thermal comfort was significantly higher during swimming than resting. Post-immersion, following maximum discomfort, in 45 of 65 tests thermal comfort improved although mean skin temperature was still cooling $(0.26$ [SD 0.19$]{ }^{\circ} \mathrm{C} \cdot \mathrm{min}^{-1}-\max$ was $\left.0.89{ }^{\circ} \mathrm{C} \cdot \mathrm{min}^{-1}\right)$. When thermal comfort was re-established mean skin temperature was lower than at maximal discomfort in 39 of 54 tests $(0.81 \text { [SD } 0.58]^{\circ} \mathrm{C}$ - max difference was $\left.2.68{ }^{\circ} \mathrm{C}\right)$. The reduction in thermal discomfort in this scenario could be due to the adaptation of thermoreceptors, or to reductions in cooling rates to levels where discomfort was less stimulated. The relief from the recent discomfort may explain why, later, thermal comfort returned to initial levels in spite of poorer thermal profiles.
\end{abstract}

Key words: Thermal comfort, skin temperature, immersion, evaporative cooling, swimming. 


\section{Introduction}

Thermal comfort is an emotional and affective experience, which depends on an individual's history and expectation [1]; it is generally defined as the condition of mind expressing satisfaction with the environmental conditions [2] and refers to the subjective indifference to this environment. It can therefore be characterised by the absence of thermal discomfort. In leisure-type scenarios thermal comfort will become important as it will affect both behaviour and pleasure responses [3]. The aim of this study was to investigate thermal comfort responses during a critical phase in recreational water-based activities: when getting out of the water and facing a wind.

Cold cutaneous thermoreceptors are temperature sensitive nerve endings situated just beneath the skin surface, where they are more densely distributed than the warm receptors [4]. Amongst the three transient receptor potential families thought to act as thermoreceptors, the transient receptor potential cation channel subfamily M member 8 (TRPM8) channel has been shown to be activated by chemical compounds including menthol $[5,6]$ and predominantly involved in the detection of environmental cold, in the range $15{ }^{\circ} \mathrm{C}$ to $25{ }^{\circ} \mathrm{C}$ [7]. In response to thermal stimuli, afferent neural information is transmitted to the thalamus for integration and to the somatosensory cortex for subjective interpretation [8].

When a sudden thermal stimulus is applied to previously thermoneutral skin, the frequency of discharge of the thermoreceptors reaches a maximum which depends upon the adapting temperature (the steady discharge observed at constant temperatures) [9]. For a given adapting temperature, this dynamic response is more intense when the cooling rate is higher $[10,11]$. Likewise, the threshold for cold sensation increases with faster cooling rates $[12$, 
10). In humans, this threshold depends upon both the cooling rate and the surface area stimulated $[4,13]$.

Following the dynamic response, the firing frequency of the thermoreceptors rapidly reduces to new static firing rate which is still above the pre-cold exposure thermoneutral static discharge frequency. Thus, the short term adaptation of the dynamic response of the cold receptors produces a new static discharge which itself disappears when the cold stimulus is removed and thermoneutrality returns and, the receptor firing frequency returns to the initial static values, corresponding to the adapting temperature [11].

Following immersion in recreational scenarios, deep body temperature is unlikely to change dramatically in the short term and skin temperature will be the primary determinant of thermal sensation and comfort. Indeed, in situations where deep body temperature remains stable, thermal comfort and skin temperature are highly correlated [14]. When wet and facing a wind, an evaporative cooling effect will be perceived, in which evaporation of water cools the skin. The extent to which wind speed will affect skin temperature following immersion may be estimated by existing predictive models [15]. However, the impact such temperature patterns will have on thermal comfort is unknown. Furthermore, little research has examined the impact on thermal comfort when wet skin of the whole body is exposed to the wind, and the effect of a prior immersion on subsequent comfort responses in air remains unexplored. A few studies have looked at human thermal responses to wet and windy environments in extreme conditions which resulted in falling skin and deep body temperatures and intense discomfort $[16 ; 17]$. It is not known what might happen in a recreational situation where the surroundings and the duration of exposure are less stressful. 
Despite extensive research on the relationships between skin temperature and thermal comfort, the effect of the direction of change of skin temperature is one factor that has received little attention. Previous pilot experiments (in water) conducted in our laboratory revealed that, with deep body temperature stable, the loss of overall thermal comfort occurred when mean skin temperature fell below approximately $31.5{ }^{\circ} \mathrm{C}$ but could be re-established below these levels if mean skin temperature was increasing then slightly increased. This suggests that in some situations absolute skin temperature could be relatively meaningless for the determination of thermal comfort in comparison with the rate of change and/or the direction of the change of skin temperature. Therefore, whether decreasing skin temperature is always experienced as uncomfortable is uncertain, as is whether increasing skin temperature is a requirement for thermal comfort to be re-established following immersion.

Water-based activities are usually associated with exercise. Several studies have investigated the impact of physical activity on deep body temperature in cool and cold water (e.g. 18) and recent work has explored the impact of physical activity on cold sensitivity [19]. However, it seems that no information is available regarding its effect on thermal comfort in cool water. Non-thermal factors have been proposed to influence subjective or perceptual responses [20, 21, 22, and 23] but no direct evidence has been provided regarding thermal comfort during immersion. We thus investigated the effect of water-based activity on overall thermal comfort. This study also explores the impact of initial values of mean skin temperature, as well as the rate, the magnitude and the direction of change of these temperatures on thermal comfort responses following immersion. It was hypothesized that following immersion, thermal comfort would only improve when mean skin temperature increases. It was also hypothesised that thermal comfort would be relatively independent of absolute mean skin temperature, and that it would be improved by exercise. 


\section{Methods}

This study was approved by the University of Portsmouth BioSciences Research Ethics committee and was performed in accordance with the ethical standards of the 1964 Declaration of Helsinki (2008). The participants gave their written informed consent to participate.

\subsection{Volunteers}

Nine male volunteers were recruited for this study (mean [SD]; Age 19.3 [1.4] yrs; height 1.8 [0.053] $\mathrm{m}$; mass $73.4[11.6] \mathrm{kg}$ ). They were instructed to avoid performing any vigorous physical activity and consuming alcohol for 24 hours prior to each test, and to avoid caffeine and hot food three hours before data collection.

\subsection{Experimental design}

The experiment was a repeated measures design in which each volunteer completed eight tests (Fig. 1), on four separate days (two tests per day). The order of the different experimental conditions followed a counterbalanced Latin square design, to which each volunteer was randomly allocated. The eight tests are shown in Figure 1, and described in more details in the following paragraphs. 


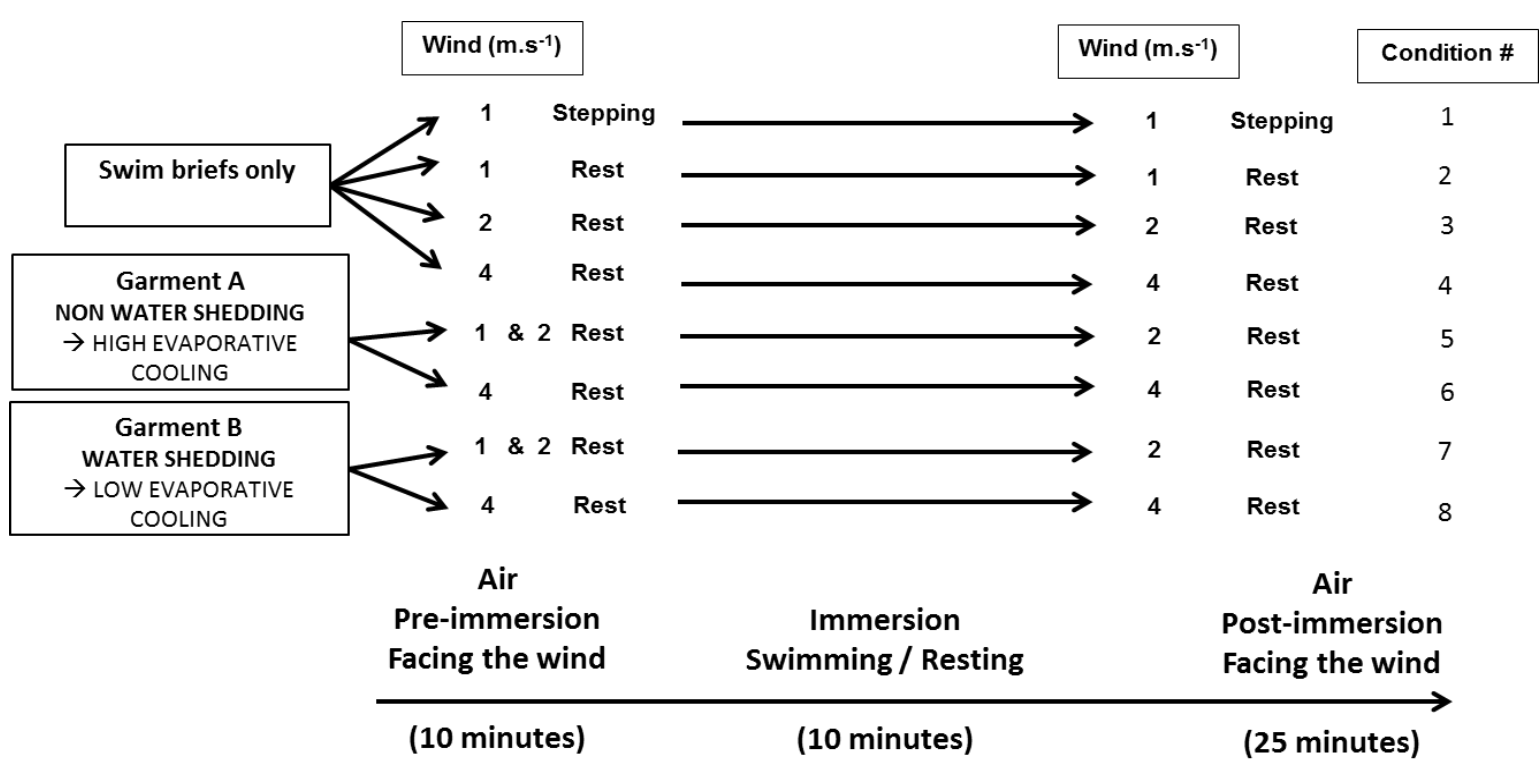

Figure 1. Experimental conditions. Three clothing conditions (on the left), three wind speeds and a resting and exercising (stepping) situation were used to produce 8 experimental conditions.

\subsection{Clothing conditions}

Beside the control conditions where volunteers wore only swim briefs (Conditions 1 to 4), the clothing consisted of a long-sleeved top, and shorts, stopping at the knees. The surface area covered was similar between the two clothing conditions, but the design and the fabrics used were different. The first assembly (“Garment $A$ ”) was a single layer of polyamide fabric that allowed water to evaporate easily. The other garment ("Garment B") was two layered with a microfleece-type fabric inner layer (polyester) while the outer layer was wind and waterproof (polyurethane), hence producing a low evaporative profile. The clothing was not, itself, being tested, it was merely used to produce different cooling and rewarming profiles.

\subsection{Pre-immersion period}

In the first stage of the experiment volunteers were exposed for 10 minutes to an air environment, with a temperature of $24{ }^{\circ} \mathrm{C}$, and relative humidity at $60 \%$ to $70 \%$. During this 
pre-immersion air exposure, whilst wearing Swim briefs (Conditions 1 to 4), volunteers stood still in front of a fan producing a turbulent flow, although air velocities were relatively uniform across the volunteers' height. In Condition 1, whilst facing air velocities of $1 \mathrm{~m} . \mathrm{s}^{-1}$ in Swim briefs, volunteers continuously stepped up and down on a $22.5 \mathrm{~cm}$ step in pace with a metronome set to stepping rate of 15 complete (up and down) steps per minute. In Conditions 2, 3 and 4, volunteers faced air velocities of $1 \mathrm{~m} \cdot \mathrm{s}^{-1}, 2 \mathrm{~m} \cdot \mathrm{s}^{-1}$ or $4 \mathrm{~m} \cdot \mathrm{s}^{-1}$ respectively, for ten minutes whilst standing at rest. In Conditions 5 and 7 , they were exposed to $1 \mathrm{~m} \cdot \mathrm{s}^{-1}$ winds for five minutes immediately followed by five minutes at $2 \mathrm{~m} \cdot \mathrm{s}^{-1}$. Finally, Conditions 6 and 8 consisted of ten minutes of wind at $4 \mathrm{~m} \cdot \mathrm{s}^{-1}$. Throughout the air exposure, and in all conditions, volunteers faced the wind.

\subsection{Immersion period}

In all conditions, following the first air exposure, volunteers immersed themselves up to the neck in a swimming flume (counter-current swimming pool) at a water temperature of $28{ }^{\circ} \mathrm{C}$, and they started alternating between swimming breast stroke and resting, for ten minutes (i.e. five 1 minute swimming periods interspersed with 1 minute rest periods). Throughout the immersion period, including the resting stages, the flume speed was $1.6 \mathrm{~km} \cdot \mathrm{h}^{-1}$.

\subsection{Post-immersion period}

Following ten minutes of immersion, the volunteers got out of the tank and for 25 minutes faced the same wind speeds as before the immersion. In Condition 1, they started stepping up and down on a step, like they did pre-immersion. In the other seven experimental conditions, they stood still until the end of the test (that is for 25 minutes). Following the first test, volunteers retained their instrumentation in place, but were rewarmed if needed in a warm 
bath, and then rested for about one hour in their own clothes, in thermoneutral air. Once rewarmed and rested, they entered the chamber for their second test of the day.

\subsection{Measurements}

\subsubsection{Skin and rectal temperatures}

Deep body temperature was continuously measured using a self-inserted rectal thermistor (Edale Instruments Ltd., UK). Once volunteers had changed into a swimming costume, they were instrumented to measure local skin temperatures; skin thermistors (Edale Instruments Ltd., UK) were attached to selected skin sites, on the right side of the body, in anatomic positions (dorsal side of hand, posterior side of forearm, outer side of upper arm, upper chest, lower back, anterior side of thigh, calf, and dorsal side of foot). Throughout the experiment, rectal and skin temperatures were recorded at 30 second intervals on electronic data loggers (Squirrel 1000 and 2040 series meter loggers; Grant Instruments [Cambridge] Ltd., UK).

\subsubsection{Thermal comfort}

Prior to the first test, volunteers were familiarized with the concept and mode of entry of the thermal comfort scales. Throughout the experiment, they were asked to report orally their overall thermal comfort to the principal investigator. This was done every 30 seconds on an imaginary "infinity" scale where volunteers chose a number corresponding to their current overall thermal comfort; the main instruction was that anything more than zero represented the comfortable side, and anything less than zero the uncomfortable side. The volunteers were told the score they gave in the last assessment and they were expected to rate their current thermal comfort relative to this previous answer. This scale was devised by the authors in order to prevent the "bottoming out" of the subjective response when people become uncomfortable; the scale was validated against a traditional categorical scale 
modified from that originally designed by Zhang (2003) [23], in that volunteers could only choose a TC category amongst those proposed on the scale: the vast majority of the negative scores on the infinity scale corresponded to the uncomfortable side of the traditional scale, and the same was observed for positive and comfortable scores. Participants were also asked every two minutes to pick one of the six categories on a classical categorical scale (A4 size): very uncomfortable, uncomfortable, just uncomfortable, just comfortable, comfortable, and very comfortable. Finally, every five minutes and only during the post-immersion period, the volunteers reported which body region was the most uncomfortable.

\subsection{Calculations}

The individual skin temperature measured on the different body sites were combined to produce a mean skin temperature $\left(\mathrm{T}_{\mathrm{sk}}\right)$ using an adjusted version of Hardy and Du Bois (1938) [24] equation to remove the head skin temperature (weighting of 0.07), which was not immersed.

$\mathrm{T}_{\mathrm{sk}}=\left(0.175 \mathrm{~T}_{\text {chest }}+0.175 \mathrm{~T}_{\text {back }}+0.07 \mathrm{~T}_{\text {upperarm }}+0.07 \mathrm{~T}_{\text {forearm }}+0.05 \mathrm{~T}_{\text {hand }}+0.19 \mathrm{~T}_{\text {thigh }}+0.13 \mathrm{~T}_{\text {calf }}\right.$ $\left.+0.07 \mathrm{~T}_{\text {foot }}\right) / 0.93$

Mean body temperature $\left(\mathrm{T}_{\mathrm{b}}\right)$ was estimated by a formula taken from the work of Frank et al. (1999) [14], who showed that skin $\left(\mathrm{T}_{\mathrm{sk}}\right)$ and rectal temperatures $\left(\mathrm{T}_{\mathrm{re}}\right)$ equally contribute to thermal comfort. Mean body temperature for thermal comfort may therefore be estimated as follows: $\mathrm{T}_{\mathrm{b}}=0.5 \mathrm{~T}_{\mathrm{re}}+0.5 \mathrm{~T}_{\mathrm{sk}}$.

\subsection{Data analyses}

The absolute thermal comfort scores given on the infinity scale were subsequently normalized within participants: for each volunteer, the lowest figure reported over the whole 
study (across the eight conditions) was attributed the score "-100", as $100 \%$ of discomfort ever experienced during the study. Similarly, the highest positive figure (corresponding to the comfortable side of the scale) reported on the infinity scale was given the score "100", as 100 $\%$ of comfort. From there, all remaining positive (or equal to zero) figures were related to this maximum comfort, and all negative figures to the maximum discomfort. All tests were conducted using SPSS 18 (Statistical Package for the Social Sciences, version 18, Chicago, USA). Before any analysis was conducted, it was confirmed that the data met the requirements and assumptions of each statistical test used. During immersion, thermal comfort scores obtained in the swimming periods were compared to those collected in the resting periods using paired-samples t-tests. Following immersion thermal comfort and physiological data sets were compared using a one-way analysis of variance and further tested using the Bonferroni post-hoc test. The alpha level was set at 0.05.

\section{Results}

\subsection{General observations}

Nine male participants were recruited for this study. They all completed the eight conditions.

\subsection{Skin temperatures}

The various experimental conditions led to different mean skin temperature profiles (Fig. 2). In all clothing conditions, during the pre-immersion period, mean skin temperature seemed to decrease with increasing air velocities: in swim briefs, the mean (SD) fall in mean skin temperature over this first air exposure was $0.9(0.6){ }^{\circ} \mathrm{C}$ and $2.7(0.7){ }^{\circ} \mathrm{C}$ when exposed to 2 $\mathrm{m} . \mathrm{s}^{-1}$ and $4 \mathrm{~m} \cdot \mathrm{s}^{-1}$ wind, respectively. When wearing Garment A (Conditions 5 and 6 ) the mean (SD) fall in mean skin temperature was $0.8(0.7){ }^{\circ} \mathrm{C}$ and $1.5(0.7){ }^{\circ} \mathrm{C}$, and was $1(0.7)$ ${ }^{\circ} \mathrm{C}$ and 1.7 (0.6) ${ }^{\circ} \mathrm{C}$ when wearing Garment B (Conditions 6 and 7). During immersion, these 
differences were reduced to a minimum as water temperature clamped skin temperature. Post-immersion, mean skin temperature initially decreased in all conditions but the rates of change and absolute changes varied. A reduction in the rate of change of mean skin temperature was then observed before mean skin temperature started to increase again in seven of the eight conditions.

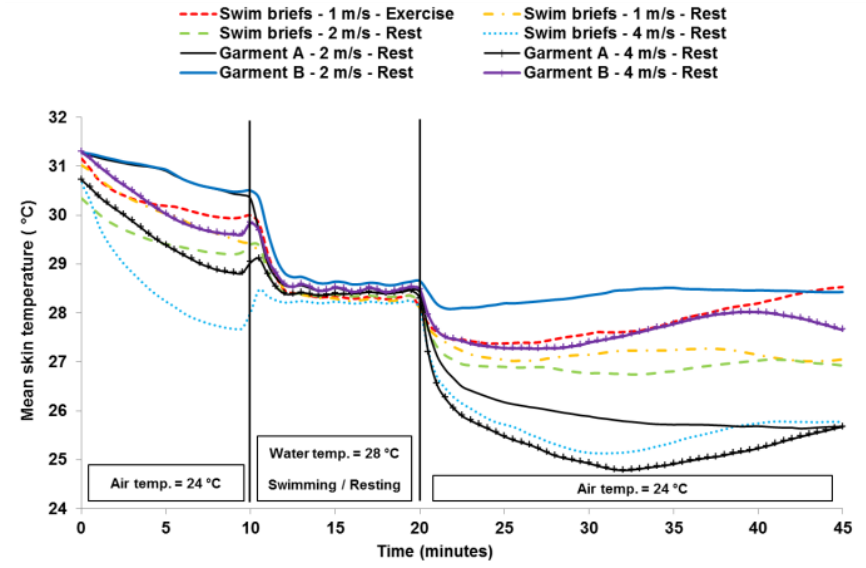

Figure 2. Average mean skin temperature of volunteers exposed to various wind speeds in different clothing, before, during, and after immersion in $28{ }^{\circ} \mathrm{C}$ water $(n=9)$. Garment A favors evaporative cooling, Garment B has a low evaporative cooling profile. Standard deviations are not presented for clarity.

\subsection{Rectal temperature}

Figure 3 shows the mean rectal temperature for each condition, throughout the experiment. During the pre-immersion period, rectal temperature increased in a similar way during both resting and exercising conditions. Then, for the seven resting conditions, a general and consistent pattern can be described: immersion soon resulted in a decrease in rectal temperature, before it started to rise again during the post-immersion period, to finally reach a plateau. However, when exercising in the Swim briefs condition (Condition 1), rectal 
temperature continuously increased during the experiment. The range of mean rectal temperature remained less than $0.5^{\circ} \mathrm{C}$.

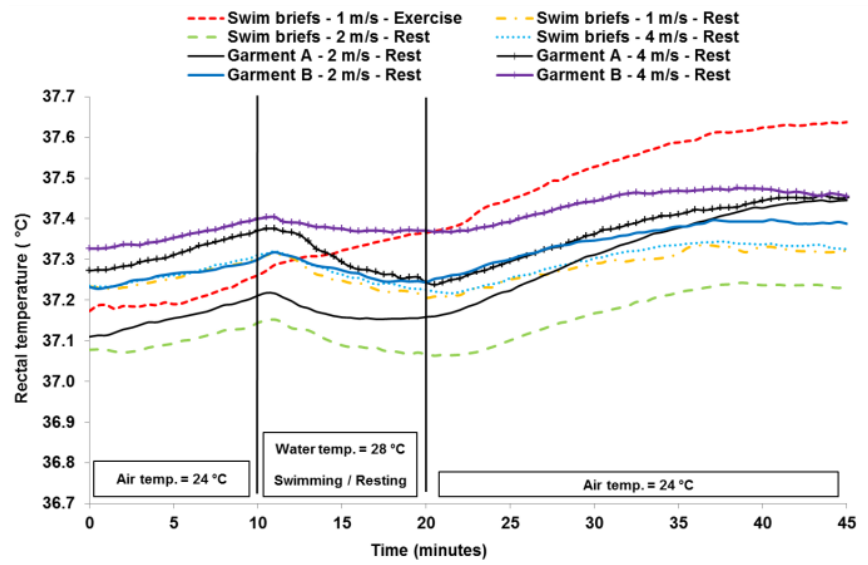

Figure 3. Mean rectal temperature of volunteers exposed to various wind speeds in different clothing, before, during, and after immersion in $28{ }^{\circ} \mathrm{C}$ water $(n=9)$. Garment A favors evaporative cooling, Garment B has a low evaporative cooling profile.

\subsection{Exercise and thermal comfort during immersion}

Table 1 shows that in five of the eight experimental conditions, mean body temperature was significantly higher in the immersion resting periods than in the swimming periods, albeit by a very small margin.

Table 1. Average (SD) mean body temperatures during 10 minutes of immersion in $28{ }^{\circ} \mathrm{C}$ water, averaged over the immersion resting periods ("rest") and the swimming periods ("swim"), in all experimental conditions. * $P<0.05(n=9)$. Garment A favors evaporative cooling, Garment B has a low evaporative cooling profile.

\begin{tabular}{|c|c|c|c|}
\hline \multirow[b]{2}{*}{ EXPERIMENTAL CONDITION } & \multicolumn{2}{|c|}{ Mean (SD) body temperatures $\left({ }^{\circ} \mathrm{C}\right)$} & \multirow[b]{2}{*}{$P$ value } \\
\hline & REST & SWIM & \\
\hline 1 - Swim briefs $-1 \mathrm{~m} \cdot \mathrm{s}^{-1}$ wind - exercise & $32.88(0.17)$ & $32.85(0.18)$ & 0.188 \\
\hline 2 - Swim briefs $-1 \mathrm{~m} \cdot \mathrm{s}^{-1}$ wind - rest & ${ }^{*} 32.83(0.21)$ & $32.79(0.18)$ & 0.0078 \\
\hline 3 - Swim briefs $-2 m \cdot \mathrm{s}^{-1}$ wind - rest & ${ }^{*} 32.75(0.11)$ & $32.74(0.11)$ & 0.0051 \\
\hline 4 - Swim briefs $-4 \mathrm{~m}^{-\mathrm{s}^{-1}}$ wind - rest & $32.75(0.18)$ & $32.74(0.17)$ & 0.222 \\
\hline 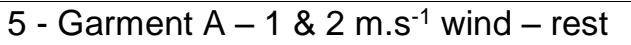 & ${ }^{*} 33.01(0.27)$ & $32.97(0.25)$ & 0.0002 \\
\hline 6 - Garment $\mathrm{A}-4 \mathrm{~m} \cdot \mathrm{s}^{-1}$ wind - rest & *32.97 (0.18) & $32.95(0.17)$ & 0.0078 \\
\hline
\end{tabular}


7 - Garment $\mathrm{B}-1 \& 2 \mathrm{~m} \cdot \mathrm{s}^{-1}$ wind - rest

8 - Garment B $-4 \mathrm{~m} \cdot \mathrm{s}^{-1}$ wind - rest

*32.85 (0.23)

Figure 4 shows that during immersion, in all but one condition (condition 7) thermal comfort was significantly higher when swimming than when resting. The analysis also revealed the significant differences seen between resting and swimming were similar in all conditions, with mean (SD) thermal comfort being 13.2 (3.1) \% greater during swimming compared to resting.

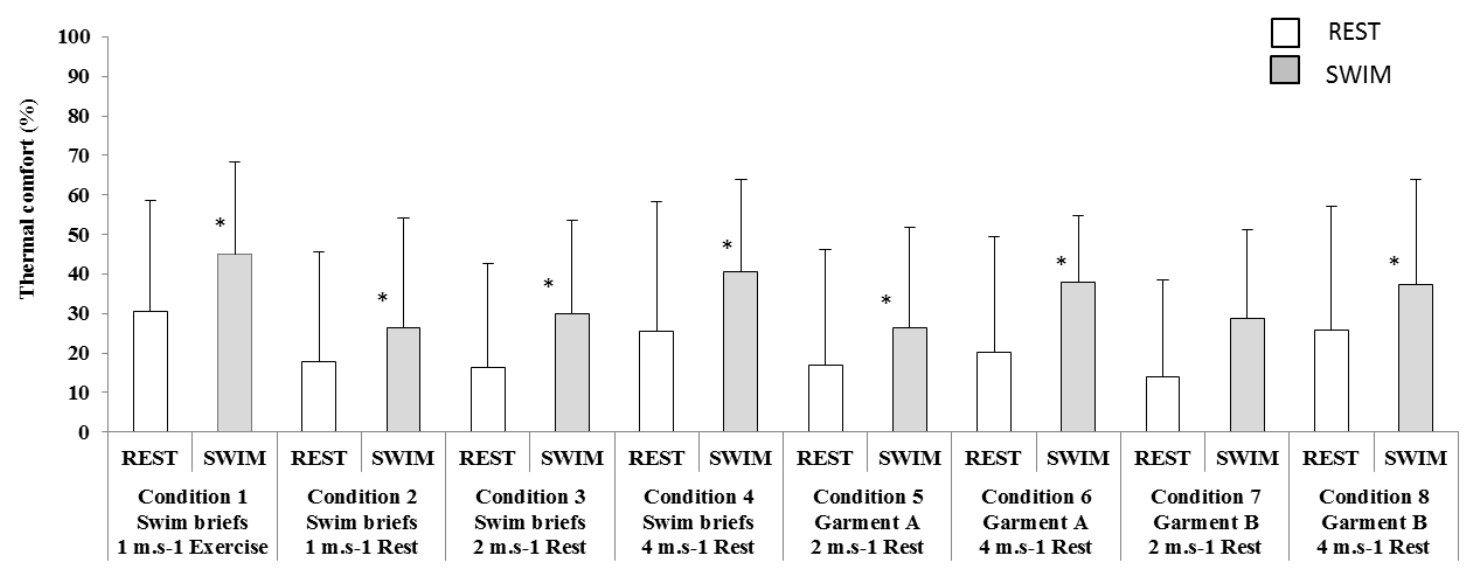

Figure 4. Mean (SD) overall thermal comfort score (normalized to maximum comfort) during the swimming and resting periods of immersion, in the eight experimental conditions. Garment A favors evaporative cooling, Garment B has a low evaporative cooling profile. $* P$ $<0.05(n=9)$. Note: *represent significant differences between resting and swimming periods, within conditions. 


\subsection{Thermal comfort following immersion}

Thermal discomfort was experienced in 65 of 72 tests. The top section of Figure 5 (5A) presents the overall thermal comfort after normalisation of the scores obtained on the infinity scale. In most conditions, four main phases can be identified in the thermal comfort data (see Fig. 5A).

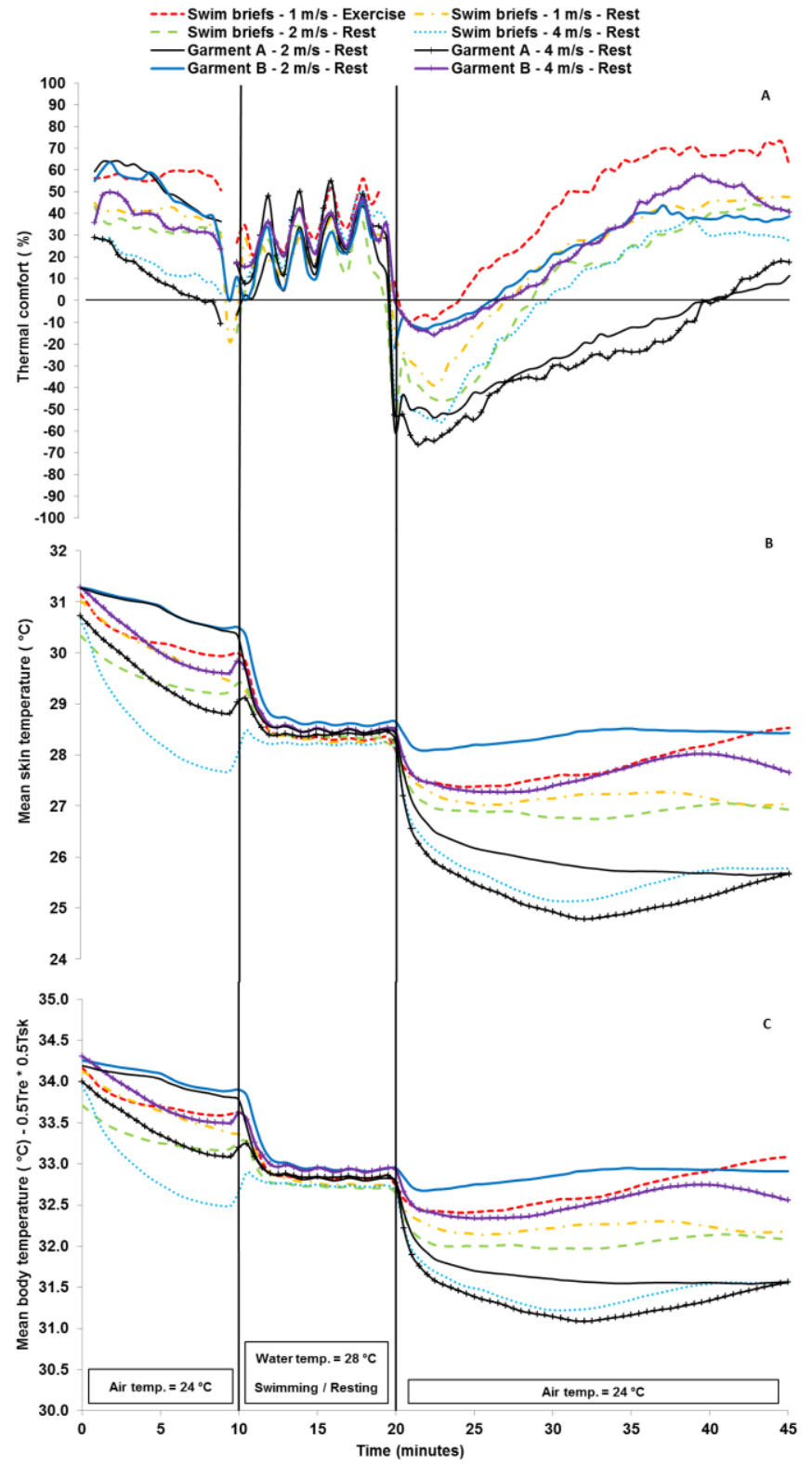


Figure 5. Mean overall thermal comfort, mean skin, and mean body temperatures during all exposures $(n=9)$. Garment A favors evaporative cooling, Garment B has a low evaporative cooling profile.

3.5.1 Phase 1: Maximum discomfort was experienced. The first phase corresponds to the first three minutes of the post-immersion period when thermal comfort reaches its lowest point.

3.5.2 Phase 2: Improvement in thermal comfort. This phase corresponds to the linear increase observed in thermal comfort, from the $23^{\text {rd }}$ to the $40^{\text {th }}$ minute of the experiment. In some Conditions 4 (Swim briefs $-4 \mathrm{~m} \cdot \mathrm{s}^{-1}$ wind - Rest), 5 (Garment A-1\& $2 \mathrm{~m} \cdot \mathrm{s}^{-1}$ wind - Rest), and 6 (Garment $A-4 \mathrm{~m} \cdot \mathrm{s}^{-1}$ wind-Rest), a linear increase occurs in thermal comfort despite a continued fall in mean skin temperature over a ten minute period $\left(23^{\text {rd }}\right.$ to $33^{\text {rd }}$ minute). In approximately $70 \%$ of the tests (45 of 65 ), during this second phase, thermal comfort was improving while mean skin temperature was still falling (Fig. 5B); mean (SD) cooling rate was $0.26(0.19){ }^{\circ} \mathrm{C} \cdot \mathrm{min}^{-1}$. Across all conditions, the maximum mean skin temperature cooling rate measured when thermal comfort started to improve was $0.89{ }^{\circ} \mathrm{C} \cdot \mathrm{min}^{-1}$. In 37 of 65 of these tests, the mean (SD) skin temperature cooling rate was $0.54(0.4){ }^{\circ} \mathrm{C} \cdot \mathrm{min}^{-1}$ slower than when the maximum discomfort was reported. The minimal reduction in the cooling rate where an increase in thermal comfort was observed was $0.07{ }^{\circ} \mathrm{C} \cdot \mathrm{min}^{-1}$. In 12 out of 65 tests, discomfort started to be reduced when mean skin temperature was stable.

\subsubsection{Phase 3: Thermal comfort re-establishment (i.e. thermal comfort votes rise above 0). Of}

72 tests, thermal discomfort was experienced in 65 tests. In 54 of these 65 tests, thermal comfort was eventually re-established. At that point, mean skin temperature was: a. increasing in less than half of these cases (25 of 54 tests); and b. lower than at the point of maximum discomfort in more than $72 \%$ of the occasions (39 of 54 tests). In these cases, 
mean skin temperature was lower by an average of $0.81(0.58){ }^{\circ} \mathrm{C}$, and the maximum value it was below the point of maximum discomfort was $2.68^{\circ} \mathrm{C}$ (found for Condition 3).

3.5.4 Phase 4: Pre-immersion thermal comfort re-established. In the last five minutes of the post-immersion period, in most conditions, thermal comfort, mean skin (Fig. 5B) and mean body (Fig. 5C) temperatures had plateaued. However, whilst thermal comfort had returned to pre-immersion levels, average (SD) mean skin temperature remained, on average, across conditions, $4(1.3){ }^{\circ} \mathrm{C}$ lower than before immersion. Although thermal comfort had returned to pre-immersion levels, mean body temperature remained, on average, across conditions, 1.9 $(0.67){ }^{\circ} \mathrm{C}$ lower than at the beginning of the experiment.

\section{Discussion}

The aims of the present work were to investigate the effect of exercise during immersion on thermal comfort, and the impact of evaporative cooling on thermal comfort following immersion. After a period of activity in the water, volunteers wearing different garments, designed to give different cooling and rewarming profiles, were exposed to various wind speeds. The large number of experimental conditions produced a wide range of thermal comfort responses.

Alternating between swimming and resting periods during immersion enabled us to investigate the impact of activity on thermal comfort. In almost all tests, thermal comfort was higher when swimming, which supports the hypothesis that exercise improves thermal comfort. This effect was similar across all clothing conditions, and was seen whether rectal temperature was increasing (due to pre-immersion exercise) or decreasing during immersion. When significant differences in mean body temperatures when resting or exercising in the 
water were observed, mean body temperature was slightly higher when resting. This is probably due to reduced convective heat loss when compared to the swimming periods, allowing skin temperature to rise by a few tenths of a degree. Thus, the positive impact of swimming on thermal comfort was probably due to the activity per se, rather than a thermal effect; recent work has shown reduced cold sensitivity of the skin at some body regions during exercise [19], but these authors did not examine the impact of activity on thermal comfort.

To the authors' knowledge, the present paper is the first to report the benefits of exercising on thermal comfort, independent of skin or rectal temperature, when swimming. Other factors that we did not measure in our study might have been involved. For example, hormonal mechanisms have been proposed to explain the influence of exercise on thermal sensitivity [21], but in our study one might expect these to still be effective during the intermittent periods of rest. In addition, exercise has been reported to influence subjective responses such as pain [25]. Finally, it has been shown that the transmission of cutaneous information to the central nervous system can be reduced by voluntary movements, probably due to inhibitory mechanisms at synapses [20]. Accordingly, it is possible that activation of mechanoreceptors during swimming partially suppressed the input of cold receptors to the somatosensory cortex. Although no evidence has ever been provided regarding thermal comfort, it seems that these neurophysiological factors cannot be ignored, and may have influenced the thermal comfort responses during swimming. It has also been shown that psychological aspects such as attention/distraction can affect the detection of thermal stimuli [22]. Thus, the focus and attention involved in swimming may have partly distracted volunteers from cold discomfort. It is interesting to note that on immersion in cool or cold water, most people would naturally start exercising, as if this was done to reduce thermal discomfort. However, unlike in air, in 
water temperatures below $25{ }^{\circ} \mathrm{C}$ (including still water) this behaviour is counter-productive as far as maintaining deep body and skin temperatures are concerned [26]. In these situations, the fall in skin and rectal temperatures would eventually impair overall thermal comfort more rapidly than at rest. Therefore, the behavioural response of swimming when entering cool and cold water demonstrates that this action is driven by perception rather than thermal responses.

Following immersion, and soon after maximum discomfort was experienced, thermal comfort started to improve again. In the majority of the tests, this occurred although mean skin temperature was still cooling. These data refute the hypothesis that thermal comfort will only improve when mean skin temperature increases. In the present situations the increase in rectal temperature is unlikely to be responsible for the reduction in thermal discomfort as only a very few minutes passed between these two consecutive stages (maximum discomfort and the beginning of thermal comfort improvement). In most of these tests, the skin temperature cooling rate was slower than when the maximum discomfort was reported. The mechanisms behind the reduction in thermal discomfort are uncertain, but must be related to diminished afferent neurophysiological input due a reduced rate of change of the temperature of cutaneous thermoreceptors, the output of which will have been the major determinant of thermal comfort in these dynamic situations.

It is important to note that although for simplicity we measured skin temperature, what the sensory cortex actually receives is neural afferent input; this usually correlates with skin temperature except in some special circumstances where skin thermoreceptors are activated without a change in temperature (e.g. stimulation by menthol [27]). In response to cooling, peripheral cold thermoreceptors demonstrate an initial dynamic peak in their impulse frequency, and then rapidly adapt by reducing this firing rate to a new, raised, static firing 
frequency [11]. This adaptation of the cold receptor afferent input may be the neurophysiological correlate of the reduction seen in thermal discomfort after the maximum level of discomfort caused by the initial dynamic maxima. Alternatively, the diminution in the rate of change of skin temperature may also have resulted in the temporal summation of the afferent thermoreceptor input falling below the level where maximum responses are evoked. The data from the present study cannot provide clear evidence of the relative contribution of these two mechanisms, but one argument in favour of an adaptation of the cutaneous thermoreceptors is that in $20 \%$ of the exposures thermal comfort started to improve as skin temperature stabilized; this constant stimulus may have enabled the rapid adaptation of peripheral receptors. The lower firing rate will have led to a decrease in cold sensation and, consequently, to the reduction of cold discomfort.

Interestingly, but in support of an important dynamic effect, in a large proportion of the tests thermal comfort was re-established although mean skin temperature was lower than when the maximum discomfort was experienced. This supports the hypothesis that thermal comfort will be relatively independent of absolute mean skin temperature. In most conditions, thermal comfort was re-established within the first 10 minutes post-immersion, and over that short period rectal temperature had increased on average by less than $0.1^{\circ} \mathrm{C}$. Although we cannot exclude the possibility that this internal input influenced overall thermal comfort, the increase is likely to have been too small to compensate for the fall in mean skin temperature. Moreover, during the last minutes of the tests, thermal comfort was often re-established to pre-immersion levels (and sometimes even higher), although mean skin temperature was several degrees lower than pre-immersion. 
To explore the extent to which this was due to an integration of thermal afferents from rectal and skin temperatures, the patterns of mean body temperatures were compared to those of thermal comfort, post-immersion. Mean body temperature is generally calculated using the formula from Gagge and Nishi (1977) [29], based on the estimation of the relative and unequal contributions of the "core" and the "shell" of the body for heat exchange estimations. A more relevant formula would perhaps be based on the measured input of these temperatures to thermal comfort. In the present study, estimations of mean body temperatures were made using the work from Frank et al. (1999) [14], who showed that skin and rectal temperature equally contribute to thermal comfort. It was observed that towards the end of the post-immersion period when thermal comfort returned to what it was at the beginning of the experiment, mean body temperature was lower than pre-immersion. To obtain mean body temperature patterns that better correlated with the thermal comfort at the end of the postimmersion period, it would be necessary to attribute an unrealistic weighting of 0.9 for rectal temperature and 0.1 for mean skin temperature. This supports the idea that thermal comfort depends on a variety of thermal and non-thermal factors, critical amongst which is rate of change of skin temperature in so far as it translates into the dynamic response of cutaneous thermoreceptors. Another possible perceptual or experiential co-factor could be that intense discomfort had recently been experienced. The relief from this stressful situation would be interpreted as a relatively pleasant feeling, producing a "very comfortable" score, despite thermal profiles that would normally lead to discomfort. This is in good agreement with other work where this "overshoot" response was observed when thermal discomfort was locally removed $[23,28]$.

In the present study, looking at young and fit adult males, it is concluded that despite similar thermal profiles, swimming is associated with higher thermal comfort than resting in cool 
moving water, probably due to a combination of physiological and psychological (distracting) responses. Post-immersion, thermal discomfort can be reduced, and thermal comfort reestablished to pre-immersion levels, despite poorer thermal profiles, most likely due to rate of change of temperature (afferent neural input) effects and ongoing comparison with recent more adverse sensations.

\section{Acknowledgements}

This study was made possible by financial support from Oxylane Research (Oxylane Group), and by the participation of brave and reliable volunteers who accepted to take part in these demanding experiments. The authors would also like to thank Mr. Alex Ouzounoglou, Mr Danny White, and Mr. Geoff Long for the great technical help. 


\section{References}

1 LeBlanc J, Ducharme MB, Pasto L, Thompson M. Response to thermal stress and personality. Physiology \& Behavior 2003;80(1):69-74.

2 ASHRAE. Thermal comfort conditions, ASRAE standard 55.66, New York; 1966.

3 Chatonnet J, Cabanac M. The perception of thermal comfort. International Journal of Biometeorology 1965;9:183-193.

4 Hardy JD, Oppel TW. Studies in temperature sensation. IV. The stimulation of cold sensation by radiation. Journal of Clinical Investigation 1938;17(6):771-778.

5 McKemy DD, Neuhausser WM, Julius D. Identification of a cold receptor reveals a general role for TRP channels in thermosensation. Nature 2002;416:52-58.

6 Peier AM, Moqrich A, Hergarden AC, Reeve AJ, Andersson DA, Story GM, Earley TJ, et al. A TRP channel that senses cold stimuli and menthol. Cell 2002;108:705-15.

7 Bautista DM, Siemens J, Glazer JM, Tsuruda PR, Basbaum AI, Stucky CL, Jordt SE, Julius D. The menthol receptor TRPM8 is the principal detector of environmental cold. Nature 2007;448:204-208.

8 McGlone F, Reilly D. The cutaneous sensory system. Neuroscience and Biobehavioral Reviews 2010;34:148-159.

9 Iggo A. Cutaneous thermoreceptors in primates and sub-primates. The Journal of Physiology 1969;200:403-430.

10 Kenshalo DR, Duclaux R. Response characteristics of cutaneous cold receptors in the monkey. Journal of Neurophysiology 1977;40(2):319-32. 
11 Hensel $\mathrm{H}$. Thermoreception and temperature regulation, Academic Press, London. Monographs of the physiological society 1981; nr. 38.

12 Kenshalo DR, Holmes CE, Wood PB. Warm and cool thresholds as a function of rate of stimulus temperature change. Attention, Perception, and Psychophysics 1966;3(2):81-84.

13 Defrin R, Petrini L, Arendt-Nielsen L. Spatial summation of thermal sensations depends on skin type and skin sensitivity. Experimental Brain Research 2009;198(1):29-36.

14 Frank MS, Raja SN, Bulcao CF, Goldstein DS. Relative contribution of core and cutaneous temperatures to thermal comfort and autonomic responses in humans. Journal of Applied Physiology 1999;86:1588-1593.

15 Huizenga C, Zhang H, Arens E, Wang D. Skin and core temperature response to partialand whole-body heating and cooling. Journal of Thermal Biology 2004;29(7-8):549-558.

16 Thompson RL, Hayward JS. Wet-cold exposure and hypothermia: thermal and metabolic responses to prolonged exercise in rain. Journal of Applied Physiology 1996;81:1128-1137.

17 Yamane M, Oida Y, Ohnishi N, Matsumoto T, Kitagawa K. Effects of wind and rain on thermal responses of humans in a mildly cold environment. European Journal of Applied Physiology 2010;109(1):117-23.

18 Golden FS, Tipton MJ. Human thermal responses during leg-only exercise in cold water. The Journal of Physiology 1987;391:399-405.

19 Ouzzahra Y, Havenith G, Redortier B. Regional distribution of thermal sensitivity to cold at rest and during mild exercise in males. Journal of Thermal Biology 2012;37(7):517-523. 
20 Ghez C, Lenzi GL. Modulation of sensory transmission in cat lemniscal system during voluntary movement. Pflügers Archives 1971;323(3):273-8.

21 Kemppainen P, Pertovaara A, Huopaniemi T, Johansson G, Karonen SL. Modification of dental pain and cutaneous thermal sensitivity by physical exercise in man. Brain Research $1985 ; 360(1-2): 33-40$.

22 Bushnell MC, Duncan GH, Dubner R, Jones RL, Maixner W. Attentional influences on noxious and innocuous cutaneous heat detection in humans and monkeys. Journal of Neurosciences 1985;5(5):1103-1110.

23 Zhang H. Human Thermal Sensation and Comfort in Transient and Non Uniform Thermal Environments. PhD Thesis 2003. University of California, Berkley, CA, 94720-1839, USA.

24 Hardy JD, Du Bois EF. The technique of measuring radiation and convection. Journal of Nutrition 1938;15(5):461-475.

25 Koltyn KF, Arbogast RW. Perception of pain after resistance exercise. British Journal of Sports Medicine 1998;32(1):20-4.

26 Keatinge WR. The effect of work and clothing on the maintenance of the body temperature in water. Quarterly journal of experimental physiology and cognate medical sciences $1961 ; 46: 69-82$.

27 Gillis DJ, House JR, Tipton MJ. The influence of menthol on thermoregulation and perception during exercise in warm, humid conditions. European Journal of Applied Physiology 2010;110(3):609-618.

28 Arens E, Zhang H, Huizenga C. Partial- and whole-body thermal sensation and comfortPart I: Uniform environmental conditions. Journal of Thermal biology 2006;31(1-2):53-59. 
29 Gagge AP, Nishi Y. (1977). Heat exchange between human skin surface and thermal environment. In: Lee DHK, ed. Handbook Physiology. Reactions to Environment Agents. American Physiology Society. Bethesda, 69-72. 